\title{
Arrhythmogenic right ventricular dysplasia: an uncommon cause of ventricular tachycardia in young and old?
}

J S McLay, A Norris, R W Campbell, F Kerr

\begin{abstract}
Right ventricular dysplasia is a little understood condition and is almost certainly underdiagnosed as an important cause of recurrent ventricular tachycardia and sudden death. This report describes two patients with right ventricular dysplasia. Their clinical presentation reflects the remarkable diversity of the disease while the potentially lifethreatening nature of their arrhythmias and their lack of response to medical treatment justified the antiarrhythmic surgical procedure of right ventricular disarticulation.
\end{abstract}

(Br Heart J 1993;69:158-160)

Arrhythmogenic right ventricular dysplasia (ARVD) is a well recognised cause of sudden death in the young. ${ }^{1}$ The term was first used by Frank et al in 1978. ${ }^{2}$ The primary histopathological features of the disorder range from localised replacement of the muscular tissue of the right ventricle with fibroadipose tissue at the subtricuspid, subpulmonary, and apical areas of the right ventricle to massive replacement of the right ventricular myocardium with fibroadipose tissue. ${ }^{13}$ In either case ventricular arrhythmias are the dominant feature. Typically, ARVD occurs in young adults with at least $80 \%$ of cases presenting before the age of 40 years. ${ }^{47}$ The most common presenting complaint is exertional fatigue or palpitation and, less commonly, syncopal attacks or sudden death. ${ }^{1489} \mathrm{We}$ report two patients with ARVD: a girl who presented with unexplained drop attacks and an elderly man with recurrent ventricular tachycardia.

\section{Case reports}

CASE 1

A white girl presented at the age of 14 years with a 12 month history of fainting episodes. During these episodes, which only occurred at school, she complained of feeling hot and dizzy before going limp and then losing consciousness for several minutes. Thereafter she made a complete recovery. Her electrocardiogram showed ventricular extrasystoles which were thought to be secondary to anxiety. An electroencephalogram was reported as being strongly suggestive of primary generalised epilepsy and this was believed to be the likely diagnosis.

Over the next 18 months the frequency of attacks rapidly decreased and so anticonvulsant therapy was withheld. She next presented four years later at the age of 18 years after having collapsed twice while dancing at a discotheque. On one occasion she was witnessed to have had an epileptiform seizure and to have been incontinent of urine. These episodes were thought to be vasovagal attacks rather than epileptic seizures because several similar attacks had been averted by lying down. Over the next 6 months, however, she was admitted to hospital on three occasions with complaints of chest pain, palpitation, and a feeling of dizziness. At this time an echocardiogram, which was not seen by us, was reported as being within normal limits, as was an exercise test. The only abnormality detected was on a 48 hour Holter monitor which showed ventricular extrasystoles associated with periods of profound sinus bradycardia ( 30 beats $/ \mathrm{min}$ ) occurring throughout the 48 hour recording and during which symptoms developed. Sick sinus syndrome was diagnosed.

Later in the same year she complained again of severe palpitation and a repeat 24 hour Holter monitor showed a two second episode of uniform ventricular tachycardia with a rate of 220 beats $/ \mathrm{min}$. Flecainide and mexiletine were unsuccessful in relieving the episodes of tachycardia so treatment with amiodarone was started. This proved successful. Despite large doses of amiodarone the episodes of ventricular tachycardia were not completely suppressed and treatment was further complicated by frank thyrotoxicosis. Echocardiography was repeated and the echocardiogram showed right ventricular dilatation suggesting right ventricular dysplasia. Right ventricular angiography confirmed a much dilated akinetic ventricle. Electrophysiological studies confirmed easily inducible uniform ventricular tachycardia with a cycle length of 320 ms. Despite the relatively long cycle length, induced ventricular tachycardia did result in haemodynamic collapse.

We did further electrophysiological studies to determine whether surgery or an implantable defibrillator was indicated. For this study catheters were placed in the right ventricular outflow tract, mid right ventricular septum, and in the upper posterior septal region of the left ventricle. Ventricular tachycardia was induced on three occasions from the left ventricle and three separate tachycardia configurations were seen. Two of these were successfully \\ Medicine and
} 18 August 1992 
mapped and both reentrant circuits were related to the right ventricular outflow tract. Because her arrhythmias were potentially life threatening and were not satisfactorily managed by drug treatment right ventricular disarticulation was recommended.

CASE 2

The second patient is a 75 year old man who first presented at the age of 64 after having collapsed in the street while shopping. On admission he had a sinus tachycardia (115 beats/min), a raised jugular venous pressure ( 6 $\mathrm{cm}$ ), and both clinical and radiological signs of pulmonary oedema. A myocardial infarction was suspected but not confirmed by serial electrocardiograms or cardiac enzymes. Over the next six years he remained well although he complained of occasional palpitation which was diagnosed as atrial fibrillation and treated with digoxin and verapamil. In April 1984 he collapsed and was found to be in ventricular tachycardia which was cardioverted. An acute subendocardial myocardial infarct was suspected by $\mathrm{T}$ wave changes. He continued to have frequent attacks of palpitation associated with ventricular tachycardia. One attack lasted three days. He was transferred to Raigmore Hospital but on arrival the rhythm had reverted to sinus.

Some months later he again presented with ventricular tachycardia that required cardioversion to restore sinus rhythm. Disopyramide, atēnolol, and amiodarone did not control further episodes of ventricular tachycardia and each produced unwanted side effects. The ventricular tachycardia was finally controlled by pindolol. In 1985 angina developed followed by several prolonged attacks of ventricular tachycardia which were treated successfully by his local general practitioner. For the next three years he remained well until a further episode of ventricular tachycardia necessitated transfer to hospital where flecainide treatment was started. A Bruce protocol exercise test, lasting eight minutes, showed infero-lateral ischaemia with no arrhythmias. Despite medical treatment ventricular tachycardia continued to occur at least once a month. All episodes required medical intervention for termination.

Cardiac catheterisation showed good left ventricular function with normal coronary arteries but a dilated right ventricle consistent with right ventricular dysplasia. ${ }^{11-13}$ Ventricular tachycardia was induced by programmed stimulation. Mapping of the arrhythmia showed its earliest activation point to be in the floor of the right ventricle with subsequent spread to the septum, the distal right ventricular apex, and the outflow tract. The failure of medical treatment, the threat to life of the ventricular tachycardia, and the patient's distance from specialised hospital facilities (domiciled on the Isle of Skye) demanded a reliable effective antiarrhythmic strategy. Right ventricular disarticulation was recommended. A partial right ventricular disarticulation was performed after which he has remained well with no further episodes of ventricular tachycardia.

\section{Discussion}

Arrhythmogenic right ventricular dysplasia is an important condition that is now attracting attention. As the name implies, arrhythmias are the hallmark of its clinical presentation. The arrhythmias range from isolated ventricular extrasystoles through ventricular tachycardia to ventricular fibrillation. Most ventricular tachycardias have a left bundle branch block configuration reflecting their right ventricular origin. Many, but not all affected patients have $T$ wave abnormalities in the right chest leads (V1-V3) during sinus rhythm. ${ }^{8}$ Echocardiography and right ventricular angiocardiography usually are diagnostic and show enlargement of the right ventricle with diminished contractility. Probably very many patients go undetected. Palpitation, syncope, and sudden death reflect the potentially lethal nature of the arrhythmias and it has been suggested that this condition may have been overlooked as a cause of sudden unexpected death in young adults. ${ }^{1489}$ Symptomatic presentation is typically between 7 and 40 years ${ }^{510}$ but as our experience shows arrhythmias may not start until late in life.

Recent data suggest that the condition may be inherited as an autosomal dominant with variable extension and penetrance. ${ }^{9}$ The father of our first patient was less than 40 years old when he collapsed and died while out walking. He had had one previous syncopal episode from which he had recovered. No other data are available.

The optimal management for the arrhythmias of right ventricular dysplasia is not established. Antiarrhythmic drugs are an appropriate first choice but they have only moderate efficacy. This may reflect the fact that ventricular tachycardia arises from a large stable reentrant circuit, the electrophysiology of which must be considerably changed if arrhythmia control is to be achieved. Partial and total right ventricular disarticulation are surgical procedures that electrically isolate the arrhythmogenic right ventricle from the rest of the heart. ${ }^{14}{ }^{15}$ World experience of the operation is as yet limited but early results are promising. ${ }^{14}$ In our two patients, medical treatment did not control life-threatening events and surgery offered the best management option. Subsequent follow up suggested that the management decision has been a good one given that both patients are alive and well and free of arrhythmias.

1 Thiene G, Nava A, Carrado D, Rossi L, Penneli N. Right ventricular cardiomyopathy and sudden death in young ventricular cardiomyopathy and sudden deat

2 Frank R, Fontaine G, Vedel J. Electrocardiologie de quatre cas de dysplasia ventricularire droite arythmogene. Arch Mal Coeur 1978;71:963-72.

3 Fontaine G, Frank R, Tonet J, et al. Arrhythmogenic right ventricular dysplasia: a clinical model for the study of chronic ventricular tachycardia. Jpn Circ J 1984;48: 515-38.

4 Volta SD. Arrhythmogenic cardiomyopathy of the right ventricle: thoughts on aetiology. Eur Heart $J$ 1989;10 (suppl D):2-6.

5 Blomstrom-Lundquist C, Sabel KG, Olsson B. A long term follow up of 15 patients with arrhythmogenic right ventricular dysplasia. Br Heart $J$ 1987;58:477-88.

6 Marcus F, Fontaine GH, Frank R, et al. Long term followup in patients with arrhythmogenic right ventricular disease. Eur Heart J 1989;10 (suppl D):68-73. 
7 Leclercq JF, Coumel P. Characteristics, prognosis and treatment of the ventricular arrhythmias of right ventricular dysplasia. Eur Heart $J 1989 ; 10$ (suppl D):61-7.

8 Nava A, Thiene G, Ganciani B, et al. Familial occurrence of right ventricular dysplasia. A study involving nine families. J Am Coll Cardiol 1988;12:1222-8.

9 Rossi PA. Arrhythmogenic right ventricular dysplasia-clinical features. Eur Heart J 1989;10 (suppl D):7-9.

10 Marcus F, Fontaine G, Guiraudon G, et al. Right ventricular dysplasia: a report of 24 adult cases. Circulation 1982;65:384-98.

11 Manyari DE, Duff EJ, Kostok WJ, et al. Usefulness of noninvasive studies for diagnosis of right ventricular dysplasia. Am J Cardiol 1986;57:1147-53.

12 Chiddo A, Locuratolo N, Gaglione A, et al. Right ven- tricular dysplasia: angiographic study. Eur Heart $J 1989$; 10 (suppl D):42-5.

13 Daubert C, Mabo P, Druelles P, et al. Benefits and limits of selective right ventricular cineangiography in arrhythmogenic right ventricular dysplasia. Eur Heart $J 1989 ; 10$ (suppl D):46-8.

14 Nimkhedkar K, Hilton CJ, Furniss SS, et al. Surgery for ventricular tachycardia associated with right ventricular dysplasia: Disarticulation of right ventricle in 9 of 10 cases. $J$ Am Coll Cardiol 1992;19:1079-84.

15 Guiraudon G, Fontaine G, Frank R, et al. Total disconnection of the right ventricular free wall: surgical treatment of right ventricular tachycardia associated with right ventricular dysplasia. Circulation 1983;67:463-70. 